\title{
A high-concentrate diet induced colonic epithelial barrier disruption is associated with the activating of cell apoptosis in lactating goats
}

\author{
Shiyu Tao, Yongqian Duanmu, Haibo Dong, Jing Tian, Yingdong Ni* and Ruqian Zhao
}

\begin{abstract}
Background: In ruminants, lower ruminal pH causes massive disruption of ruminal epithelial structure during periods of feeding high-concentrate diets. However, the influence of excessive organic fatty acids in the lumen of hindgut on the epithelial structure is unclear. In this study, twelve mid-lactating goats were randomly assigned to either a HC diet group ( $65 \%$ concentrate of dry matter; $n=6$ ) or a LC diet group ( $35 \%$ concentrate of dry matter; $\mathrm{n}=6$ ) for 10 weeks. The colonic epithelial structure was detected by HE staining and transmission electron microscopy (TEM), and the apoptotic status of epithelial cells was estimated by TUNEL method and caspase activities.

Results: HC goats showed higher level of free lipopolysaccharide (LPS) in rumen fluid $(p<0.01)$ but not in colonic digesta $(p>0.05)$, and higher total volatile fatty acid (VFA) concentrations in rumen fluid $(p<0.05)$ and in colonic digesta $(p<0.01)$, and higher content of starch in colonic digesta $(p<0.05)$ compared to LC goats. HC goats demonstrated profound alterations in the colonic epithelial structure and tight junctions (TJ), apparently due to damage of the epithelium with widened TJs space and nuclear breakdown and mitochondrial swelling. HC goats showed higher level of apoptosis in the colonic epithelium with higher proportion of TUNEL-positive apoptotic cells and increases of caspase-3 and $-3 / 7$ activities, as well as the lower ratio of bcl-2/bax mRNA expression in the colonic mucosa $(p<0.05)$. However, $\beta$-defense mRNA was significantly down-regulated in the colonic mucosa of HC goats compared to LC $(p<0.05)$. HC goats showed higher level of TJ proteins including claudin-1 and claudin-4 in the colonic mucosa than LC $(p<0.05)$. Neither free LPS content in the colonic digesta nor NF-K B protein expression in tissues showed significant difference between HC and LC goats $(p>0.05)$.
\end{abstract}

Conclusions: Our results reveal that long-term feeding $\mathrm{HC}$ diet to lactating goats causes severe damages to the colonic mucosa barrier associated with activating cells apoptosis.

Keywords: LPS, Apoptosis, Tight junctions, Colonic mucosa, HC diet, Goat

\section{Background}

In current intensive production system, large amounts of cereal grains or easily degradable byproducts in diet are fed to lactating cows to meet energy requirement for supporting maintenance and high milk yields. Excessive amounts of rapidly fermentable nonstructural carbohydrates increase the accumulation of organic acids and shift of microbial population in gastrointestinal (GI) tract in ruminants [1,2]. It's well documented that feeding high amounts of concentrate diet to ruminants results in

\footnotetext{
* Correspondence: niyingdong@njau.edu.cn

Key Laboratory of Animal Physiology \& Biochemistry, Ministry of Agriculture, Nanjing Agricultural University, Nanjing, Jiangsu, China
}

subacute ruminal acidosis (SARA), a common metabolic disease especially occurred in high-producing animals. Lower $\mathrm{pH}$ due to the increase of short-chain fatty acids including lactic acid and volatile fatty acids (VFA) in rumen and higher endotoxin production derived from Gramnegative bacteria lead to the sever damages to rumen epithelium during SARA or acute ruminal acidosis. Previous studies mainly focused on the effects of feeding high-grain diet on the histological structure and functions of ruminal epithelium in dairy cows $[3,4]$. Compared to rumen epithelium with a stratum corneum layer and multicellular layers in the middle [5-7], the large intestine epithelium is much more "leaky" due to the monolayer structure [8]. In addition, the natural defense against ruminal acidosis such 
as saliva bicarbonate and Protoroa organisms with capacity of slowing $\mathrm{pH}$ down is lacking in the hindgut [9]. Therefore, differences in buffering capacity and histological structure between the rumen and hindgut make the hindgut less capable of maintaining digesta $\mathrm{pH}$ and microbial population during times of increased VFA production [10].

$\mathrm{pH}$ value is an extremely important factor to determine the status of epithelial barrier. Lan et al. reported that in HT-29 human colon adenocarcinoma cell line, short-chain fatty acids (SCFA) treatment in the $\mathrm{pH}$ range of 6.0 to 7.0 induced cell apoptosis rather than necrosis, while SCFA treatment at $\mathrm{pH} 5.5$ caused cell necrosis [11]. Higher acidity induces apoptosis and inhibits cell proliferation in colorectal carcinoma cell lines [12]. In ruminants, high-grain diet led to an increase of acidity in intestinal tract, and the detrimental intestinal tract environment may cause apoptosis in the gut epithelium [10]. It's well documented that several pathways are involved in cell apoptotic programs. One is mediated by the formation of the death-inducing signaling complex and activation of caspase- 8 and caspase-10, two initiator caspases that in turn activate downstream effector of caspase-3 [13]. Another is mediated by proapoptotic signals at the mitochondria level including B-cell lymphoma 2 (Bcl-2) family and caspase-9 [14]. In epithelial tissues, tight junction damage or disruption is usually thought of as a downstream consequence of caspase cleavage during the apoptotic process [15].

As a physical barrier, intestinal epithelial mucosa separates the toxic compounds from the deeper intestinal layers $[16,17]$. Toll-like receptors (TLRs) in the gut epithelium play a key role in maintaining the homeostasis by recognizing ligands known as microbial-associated molecular patterns (MAMPs) derived from both pathogenic and non-pathogenic bacteria [18-20]. After combining with TLR-4 on the host cell surface, LPS activates myeloid differentiating factor 88 (MyD88), and then elicits a pro-inflammatory NF-k B-dependent signaling cascade $[21,22]$. As a major transcription factor and a first responder to harmful cellular stimuli, NF- $\mathrm{kB}$ plays a central role in inflammation through its ability to induce transcription of pro-inflammatory genes [23]. Diverse stimuli (e.g., microbial products, microbes, pro-inflammatory cytokines, and oxidative stress) can activate NF- $\mathrm{kB}$, and the downstream cytokines have been used to assess inflammation $[24,25]$. NF- $\mathrm{kB}$ activation has been detected in the mucosa of patients with inflammatory bowel disease (IBD) and in murine colitis model, and inhibition of NF- $\mathrm{kB}$ with a specific p65 antisense oligonucleotide is effective in preventing experimental models of IBD and efficiently down-regulates cytokine production [26]. It's reported that the accumulation of free LPS in epithelial lumen will damage the integrity and permeability of epithelial barrier in rumen as well as in large intestine [8]. However, to our knowledge, after feeding high-grain diet for a long-term the changes of LPS signaling cascade in the hindgut mucosa of ruminants are still unknown.

Tight junctions (TJs) play an important role in maintaining the polarity of epithelial cells, regulating the permeability of the epithelial barrier and preventing the translocation of LPS and other toxic compounds from intestinal tract into circulating system [5,6]. To date, information regarding the effect of feeding ruminants with diet enriched high level of concentrate on epithelial structure in the hindgut is not available. Therefore, the objectives of this study were to investigate the changes of histological structure and ultrastructure of the colonic mucosa, and the status of epithelial cells apoptosis in mid-lactating goats fed a high concentrate diet for a long period.

\section{Methods}

\section{Animals and experimental procedures}

Twelve mid-lactating goats with approximately $49.7 \pm$ $5.5 \mathrm{~kg}$ body weight were used in this study. Two weeks before the start of this experiment, goats were offered free access to a diet containing a forage-to-concentrate ratio (F: C) of 65:35 to ensure adaptation to the diet. After dietary adaptation, goats were randomly allocated to two groups. One group was fed a control diet comprising $65 \%$ forage and $35 \%$ mixed concentrate (low concentrate group, LC), while the other group received a high-grain diet containing $65 \%$ mixed concentrate and $35 \%$ forage (high concentrate group, $\mathrm{HC}$ ). The details of the diet components and nutrient compositions were shown in Table 1 . The animals were fed the respective diets for 10 weeks, and had free access to water during the experimental period.

The protocol for the care, handling and use of animals followed the ARRIVE guidelines and was approved by Animal Ethics Committee at Nanjing Agricultural University, China. The sampling procedures complied with the "Guidelines on Ethical Treatment of Experimental Animals" (2006) No. 398 set by the Ministry of Science and Technology, China and "the Regulation regarding the Management and Treatment of Experimental Animals" (2008) No. 45 set by the Jiangsu Provincial People's Government.

The ARRIVE guidelines was provided as Additional file 1.

\section{Samples collection}

After 10 weeks feeding, goats were slaughtered after overnight fasting. Immediately after slaughter, the abdominal cavity was opened by midline incision, after that the rumen and intestinal tract were carefully removed. The rumen was opened from the dorsal side and rumen fluid was collected and strained through four layers of 


\begin{tabular}{|c|c|c|}
\hline \multirow[t]{2}{*}{ Items } & \multicolumn{2}{|c|}{ The ratio of concentrate to forage } \\
\hline & $35: 65$ & $65: 35$ \\
\hline \multicolumn{3}{|l|}{ Ingredients (\% of DM) } \\
\hline Leymus chinensis & 52.0 & 28.0 \\
\hline Medicago sativa hay & 13.0 & 7.0 \\
\hline Corn & 25.6 & 25.0 \\
\hline Wheat bran & 0 & 30.7 \\
\hline Soybean meal & 7.4 & 2.2 \\
\hline Rape seed meal & 0 & 4.0 \\
\hline Limestone meal & 0.5 & 1.5 \\
\hline Calcium phosphate dibasic & 0.8 & 0.7 \\
\hline Salt & 0.4 & 0.4 \\
\hline Premix $^{1}$ & 0.4 & 0.5 \\
\hline Total & 100 & 100 \\
\hline \multicolumn{3}{|l|}{ Nutrient levels ${ }^{2}(\%)$} \\
\hline Net energy(MJ/kg) & 5.16 & 5.78 \\
\hline Digestible crude protein & 7.31 & 8.05 \\
\hline Crude protein & 12.17 & 13.42 \\
\hline Neutral detergent fiber & 34.76 & 39.06 \\
\hline Acid detergent fiber & 22.85 & 21.99 \\
\hline Calcium & 0.72 & 1.04 \\
\hline Phosphorus & 0.35 & 0.53 \\
\hline
\end{tabular}

${ }^{1}$ Provided per kg of premix: Vitamin A $6000 \mathrm{U}$; Vitamin D2 500U; Vitamin E 80 mg; Cu 6.25 mg; Fe 62.5 mg; Zn 62.5 mg; Mn 50 mg; I 0.125 mg; Co $0.125 \mathrm{mg}$; Mo $0.125 \mathrm{mg}$.

${ }^{2}$ Nutrient levels were estimated from the current goat foods.

cheesecloth and kept on ice until processing. Digesta from the proximal colon was aseptically collected and kept on ice until being stored at $-20^{\circ} \mathrm{C}$. Within $20 \mathrm{~min}$ after slaughter, a segment of the colon wall from the same position of each animal was collected and the conlonic epithelium was separated from the muscular layers by blunt dissection and immediately washed three times in ice-cold phosphate buffered saline (PBS buffer). The tissue samples were frozen immediately in liquid nitrogen, and then used for extracting RNA and proteins.

\section{Rumen fluid sampling and assay}

The rumen fluid was collected and divided into 2 portions. The first portion of each sample was transferred into a $50-\mathrm{mL}$ sterile tube and kept on ice until transported to the laboratory for the initial processing before LPS determination as described by [27]. Briefly, rumen fluid samples were centrifuged at $10,000 \times \mathrm{g}$ for $45 \mathrm{~min}$ at $4^{\circ} \mathrm{C}$ and the supernatant was aspirated gently to prevent its mixing with the pellet and passed through a disposable $0.22-\mu \mathrm{m}$ LPS-free filter. The filtrate was collected in a sterile glass tube (previously heated at $180^{\circ} \mathrm{C}$ for $4 \mathrm{~h}$ ) and heated at $100^{\circ} \mathrm{C}$ for $30 \mathrm{~min}$. Samples were cooled at room temperature $\left(25^{\circ} \mathrm{C}\right)$ for $10 \mathrm{~min}$ and stored at $-20^{\circ} \mathrm{C}$ for LPS analysis. The second portion of each rumen fluid sample was centrifuged at $3,000 \times \mathrm{g}$ for $15 \mathrm{~min}$ at $4{ }^{\circ} \mathrm{C}$ immediately after collection and the supernatant was collected. To analyze VFA in ruminal fluid, a 5-mL aliquot was deproteinized with $1 \mathrm{~mL}$ of $25 \%$ metaphosphoric acid. These samples were stored at $-20^{\circ} \mathrm{C}$ until analysis.

The concentration of LPS in rumen fluid was measured by a Chromogenic End-point Tachypleus Amebocyte Lysate Assay Kit (Chinese Horseshoe Crab Reagent Manufactory Co. Ltd, Xiamen, China). Pretreated rumen fluid samples were diluted until their LPS concentrations were in the range of 0.1 to 1 endotoxin units $(\mathrm{EU}) / \mathrm{mL}$ relative to the reference endotoxin, and assayed as described by [27]. VFA were measured using capillary column gas chromatography (GC-14B, Shimadzu, Japan; Capillary Column: $30 \mathrm{~m} \times 0.32 \mathrm{~mm} \times 0.25 \mathrm{~mm}$ film thickness; Column temperature $=110^{\circ} \mathrm{C}$, injector temperature $=$ $180^{\circ} \mathrm{C}$, detector temperature $=180^{\circ} \mathrm{C}$ ).

\section{Colonic digesta sampling and assay}

Colonic digesta samples were mixed thoroughly with an equal amount of physiological saline $(0.90 \% \mathrm{wt} / \mathrm{vol}$ of $\mathrm{NaCl})$. The mixtures were immediately centrifuged at $3,000 \times \mathrm{g}$ for $15 \mathrm{~min}$ and the supernatants were stored at $-20^{\circ} \mathrm{C}$ until analyzed for LPS and VFA detection. $10 \mathrm{~g}$ of sample was transferred into a pyrogen-free tube with $10 \mathrm{~mL}$ of physiological saline and mixed vigorously. Samples were then processed and analyzed for LPS and VFA using the same procedure described earlier for rumen fluid samples. The LPS concentration in colonic digesta samples was expressed as endotoxin units (EU) per gram of wet sample.

Colonic digesta samples were dried at $60^{\circ} \mathrm{C}$ for $48 \mathrm{~h}$. Dried samples were subsequently ground using a Wiley mill through a 1-mm screen (Thomas-Wiley, Philadel-phia, PA) and stored at $-20^{\circ} \mathrm{C}$ until analyzed for starch using a Total Starch assay kit (Comin Biotechnology Co. Ltd, suzhou, China).

\section{Caspase- 3 and $-3 / 7$ activity assay}

Caspase- 3 enzyme activity of the colonic mucosa tissue was measured by caspase activity Assay Kit (Jiancheng Bioengineering Institute, nanjing, China). And caspase3/7 enzyme activity Assay Kit was purchased from Sigma (St. Louis, MO, USA). The procedures were performed according to the manufacture's instruction.

\section{Histopathology, transmission electron microscopy and TUNEL}

Specimens of the intestinal wall of the colonic mucosa were prepared for histological examination by fixing in $4 \%$ formaldehyde-buffered solution, embedding in paraffin, 
and sectioning. Specimens were examined for injury after hematoxylin and eosin (H\&E) staining as described by $[28]$.

Colonic mucosa tissue samples were separated and fixed immediately with $2 \%$ glutaraldehyde, post-fixed with $1 \%$ osmium tetroxide, and embedded in resin. Ultrathin sections were cut and stained with uranyl acetate and lead citrate. Epithelial tissues ultrastructure was determined with a transmission electron microscope (Hitachi H-7650, Hitachi Technologies, Tokyo, Japan).

Apoptotic epithelial cells in colonic tissue were analyzed using the terminal deoxynucleotidyl transferase (TdT)-mediated dUTP-biotin nick end labeling (TUNEL) assay according to the manufacturer's instruction. Apoptosis detection kit was supplied by Boster Bio-engineering limited company (Wuhan, China). TUNEL-positive nuclei were clearly identified as brown-stained nuclei, which indicated the presence of DNA fragmentation due to apoptosis. TUNEL-positive cells were determined by observing 1000 cells in randomly selected fields.

\section{RNA isolation, CDNA synthesis and real-time PCR}

Colonic mucosa tissue was quickly collected and immediately frozen in liquid nitrogen, and stored at $-80^{\circ} \mathrm{C}$ until RNA isolation. Total RNA was extracted from colon samples with Trizol Reagent (15596026, Invitrogen). Concentration and quality of the RNA were measured by NanoDrop ND-1000 Spectrophotometer (Thermo, USA). Then two micrograms of total RNA were treated with RNase-Free DNase (M6101, Promega, USA) and reversetranscribed according to manufacturer's instructions. Two microliter of diluted cDNA (1:40, vol/vol) was used for real-time PCR which was performed in Mx3000P (Stratagene, USA). GAPDH, which is not affected by the experimental factors, was chosen as the reference gene. All the primers chosen to study the expression of genes related to TJs and apoptosis, as listed in Table 2, were synthesized by Generay Company (Shanghai, China). The method of $2^{-\Delta \Delta \mathrm{Ct}}$ was used to analyze the real-time PCR results and gene mRNA levels were expressed as the fold change relative to the mean value of control group.

\section{Western blotting analysis}

$100 \mathrm{mg}$ frozen colonic mucosa tissue was minced and homogenized in $1 \mathrm{~mL}$ of ice-cold homogenization buffer RIPA containing the protease inhibitor cocktail Complete EDTA-free (Roche, Penz-berg, Germany). The homogenates were centrifuged at $12,000 \mathrm{rpm}$ for $20 \mathrm{~min}$ at $4^{\circ} \mathrm{C}$ and then collected the supernatant fraction. Protein concentration was determined using a BCA Protein Assay kit (Pierce, Rockford, IL, USA). Eighty micrograms of protein extract from each sample was then loaded onto $7.5 \%$ and $15 \%$ SDS-PAGE gels and the separated proteins were
Table 2 PCR primer sequences of the target genes

\begin{tabular}{|c|c|c|c|}
\hline $\begin{array}{l}\text { Target } \\
\text { genes }\end{array}$ & $\begin{array}{l}\text { Reference/ } \\
\text { Genbank } \\
\text { accession }\end{array}$ & $\begin{array}{l}\text { PCR products } \\
\text { (bp) }\end{array}$ & Primer sequences \\
\hline \multirow[t]{2}{*}{ GAPDH } & HM043737.1 & 180 & $\begin{array}{l}\text { F: 5'-GGGTCATCATCTCTGC } \\
\text { ACCT -3' }\end{array}$ \\
\hline & & & $\begin{array}{l}\text { R: 5'-GGTCATAAGTCCCTCCA } \\
\text { CGA -3' }\end{array}$ \\
\hline \multirow[t]{2}{*}{ Occludin } & BC133617.1 & 200 & $\begin{array}{l}\text { F: 5'-GTTCGACCAATGCTCTC } \\
\text { TCAG -3' }\end{array}$ \\
\hline & & & $\begin{array}{l}\text { R: } 5^{\prime} \text {-CAGCTCCCATTAAGGTT } \\
\text { CCA -3' }\end{array}$ \\
\hline \multirow[t]{2}{*}{ Claudin-1 } & HM117762.1 & 216 & $\begin{array}{l}\text { F: 5'-CACCCTTGGCATGAAGT } \\
\text { GTA-3' }\end{array}$ \\
\hline & & & $\begin{array}{l}\text { R: 5'-AGCCAATGAAGAGAGC } \\
\text { CTGA -3' }\end{array}$ \\
\hline \multirow[t]{2}{*}{ Claudin-4 } & HM117763.1 & 238 & $\begin{array}{l}\text { F: 5'-AAGGTGTACGACTCGCT } \\
\text { GCT-3' }\end{array}$ \\
\hline & & & $\begin{array}{l}\text { R: 5'-GACGTTGTTAGCCGTCC } \\
\text { AG-3' }\end{array}$ \\
\hline \multirow[t]{2}{*}{$\beta$-defensin } & HM593790.1 & 165 & $\begin{array}{l}\text { F: 5'- CTGCTGGGTCAGGAT } \\
\text { TTAC -3' }\end{array}$ \\
\hline & & & $\begin{array}{l}\text { R: 5'- GCGTCTTCGCCTTCTG } \\
\pi-^{\prime}\end{array}$ \\
\hline \multirow[t]{2}{*}{$\mathrm{BCl}-2$} & AY423861.1 & 208 & $\begin{array}{l}\text { F: } 5^{\prime}-\text { TCGCCCAAGTCAAACAT } \\
\text { TA-3' }\end{array}$ \\
\hline & & & $\begin{array}{l}\text { R: 5'- CACAGGTGAAACTGCC } \\
\text { AAGAT-3' }\end{array}$ \\
\hline \multirow[t]{2}{*}{ Bax } & AF163774.1 & 178 & $\begin{array}{l}\text { F: 5'-TGCTCACTGCCTCACTC } \\
\text { AC-3' }\end{array}$ \\
\hline & & & $\begin{array}{l}\text { R: } 5^{\prime}-C C A A G A C C A C T C C T C C \\
\text { CTA-3' }\end{array}$ \\
\hline
\end{tabular}

transferred onto the nitrocellulose membranes (Bio Trace, Pall Co, USA). After transfer, membranes were blocked for $2 \mathrm{~h}$ at room temperature in blocking buffer and then membranes were incubated with the following primary antibodies: rb-anti-NF-kB p65 (1:500; sc-372, Santa cruz), m-anti-occludin (1:500; 33-1500, Invitrogen), rb-anticlaudin-1 (1:200; sc-28668, Santa cruz), m-anti-claudin-4 (1:500; 32-9400, Invitrogen), rb-anti-actived-caspase-3 (1:500; BS7004, Bioworld) and GAPDH (1:10000; AP0066, Bioworld) in dilution buffer overnight at $4^{\circ} \mathrm{C}$. After several times washes in Tris-Buffered-Saline with Tween (TBST), membranes were incubated with goat anti-rabbit or goat anti-mouse horseradish peroxidase (HRP)-conjugated secondary antibodies (1:10000; Bioworld, USA) in dilution buffer for $2 \mathrm{~h}$ at room temperature. Finally, the blot was washed and detected by enhanced chemiluminescence's (ECL) using the LumiGlo substrate (Super Signal West Pico Trial Kit, Pierce, USA), and the signals were recorded by an imaging System (Bio-Rad, USA), and analyzed with Quantity One software (Bio-Rad, USA). 


\section{Statistical analysis}

Data are presented as means \pm SE. Statistical significance was assessed by the independent sample t-test using SPSS (SPSS version 11.0 for Windows; SPSS Inc., Chicago, IL, USA) software packages. Data was considered statistically significant when $P<0.05$. Numbers of replicates used for statistics are noted in the Tables and Figures.

\section{Results}

Volatile fatty acid (VFA) and LPS concentrations in rumen fluid and colonic digesta

Concentrations of propionate $(p<0.01)$, butyrate $(p<0.01)$, isobutyrate $(p<0.05)$, valerate $(p<0.01)$, isovalerate $(p<$ $0.001)$ and total VFA $(p<0.05)$ in rumen fluid were significantly increased in $\mathrm{HC}$ goats compared to LC. The level of acetate $(p<0.01)$, propionate $(p<0.05)$, butyrate $(p<0.01)$ and total VFA $(p<0.01)$ concentrations in colonic digesta of $\mathrm{HC}$ goats was significantly higher than that of LC goats. As shown in Table 3, HC goats showed markedly higher level of free LPS concentration in rumen fluid than LC goats $(p<0.01)$, while there was no significant difference of free LPS concentration in colonic digesta between $\mathrm{HC}$ and LC goats $(p>0.05)$. Additionally, starch content in colonic

Table 3 The effect of feeding LC or HC diet on rumen fermentation and colonic digesta parameters in goats at the time of slaughter

\begin{tabular}{|c|c|c|c|}
\hline Item & LC & $\mathrm{HC}$ & P-value \\
\hline \multicolumn{4}{|l|}{ Rumen fluid } \\
\hline Free LPS, EU/mL & $25201 \pm 3398$ & $48395 \pm 4723$ & 0.004 \\
\hline Total VFA, mM & $90.20 \pm 3.55$ & $116.37 \pm 8.14$ & 0.023 \\
\hline Acetate, mM & $58.28 \pm 2.45$ & $65.48 \pm 5.45$ & 0.291 \\
\hline Propionate, mM & $16.14 \pm 0.55$ & $22.03 \pm 1.24$ & 0.003 \\
\hline Butyrate, mM & $10.65 \pm 0.77$ & $21.36 \pm 1.79$ & 0.001 \\
\hline Isobutyrate, mM & $1.73 \pm 0.06$ & $2.12 \pm 0.14$ & 0.044 \\
\hline Valerate, Mm & $1.26 \pm 0.08$ & $1.92 \pm 0.12$ & 0.002 \\
\hline Isovalerate, mM & $2.14 \pm 0.06$ & $2.95 \pm 0.12$ & 0.000 \\
\hline Acetate: Propionate & $3.61 \pm 0.12$ & $2.96 \pm 0.14$ & 0.007 \\
\hline \multicolumn{4}{|l|}{ Colon digesta } \\
\hline Free LPS,EU/mL & $22527 \pm 5325$ & $33613 \pm 5390$ & 0.182 \\
\hline Starch, mg/g mass & $3.42 \pm 0.51$ & $4.56 \pm 0.93$ & 0.042 \\
\hline Total VFA, mM & $44.68 \pm 3.35$ & $59.01 \pm 2.51$ & 0.007 \\
\hline Acetate, mM & $26.54 \pm 1.97$ & $36.58 \pm 2.08$ & 0.007 \\
\hline Propionate, mM & $10.79 \pm 0.88$ & $13.23 \pm 0.55$ & 0.037 \\
\hline Butyrate, mM & $4.44 \pm 0.54$ & $6.26 \pm 0.25$ & 0.010 \\
\hline Isobutyrate, mM & $2.37 \pm 1.46$ & $0.85 \pm 0.04$ & 0.280 \\
\hline Valerate, Mm & $1.07 \pm 0.04$ & $1.21 \pm 0.06$ & 0.130 \\
\hline Isovalerate, mM & $0.95 \pm 0.03$ & $0.88 \pm 0.03$ & 0.172 \\
\hline Acetate: Propionate & $2.47 \pm 0.04$ & $2.78 \pm 0.16$ & 0.126 \\
\hline
\end{tabular}

Values are mean $\pm S E M, n=6$ digesta of $\mathrm{HC}$ goats was markedly higher than that in LC goats $(p<0.05)$ (Table 3$)$.

\section{Caspase activities in the colonic mucosa}

As shown in Figure 1, HC goats showed a significant increase of caspase- 3 activity $(p<0.05)$ and a tendency increase of caspase-3/7 activity $(p=0.07)$ in colonic mucosa compared to LC.

\section{Morphology, ultrastructure and TUNEL of the colon epithelium}

HE staining showed that indentations, severe cellular damage and crypts necrosis were observed in the colonic epithelium of $\mathrm{HC}$ but not LC goats (Figure 2A and B). The TJ and epithelium apoptosis in the colonic epithelium was detected by Transmission Electron Microscopy (TEM) method. TJs in the colonic epithelium of HC goats were damaged with wider intercellular space (Figure 3A and D), while LC goats displayed integrity and normal TJs structure. Moreover, LC goats showed normal cell nucleus and mitochondria structure (Figure $3 \mathrm{~B}$ and $\mathrm{C}$ ), whereas $\mathrm{HC}$ goats displayed apparent nuclear breakdown and mitochondrial swelling (Figure 3E and F). As shown in Figure 4, the proportion of TUNEL-positive apoptotic cells in the colonic epithelium of $\mathrm{HC}$ goats was markedly increased compared to LC goats $(p<0.05)$.

\section{Gene expression in the colonic mucosa}

In the colonic mucosa, $\beta$-defensin and the ratio of bcl-2/ bax mRNA expression was significant decreased in $\mathrm{HC}$ goats compared to control $(p<0.05)$. There was a tendency increase in mRNA expression of claudin-1 in HC goats $(p=0.084)$. However, the mRNA expression of occludin and claudin-4 in the colonic mucosa did not

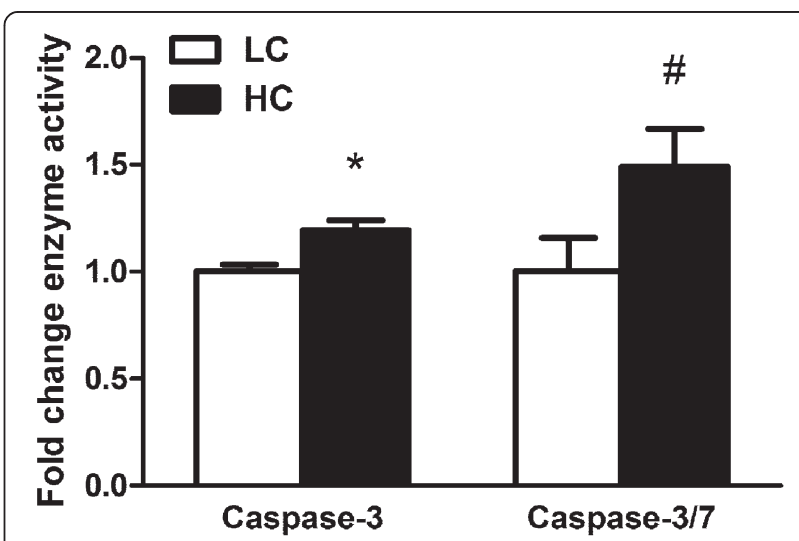

Figure 1 Caspase- 3 and caspase-3/7 enzyme activity in the colonic mucosa. The results were expressed as mean \pm SEM. The data were analyzed by Independent-Samples $T$ test using the Compare Means of SPASS 11.0 for Windows (StaSoft Inc, Tulsa, OK, USA). ${ }^{*} p<0.05$ vs. LC. 


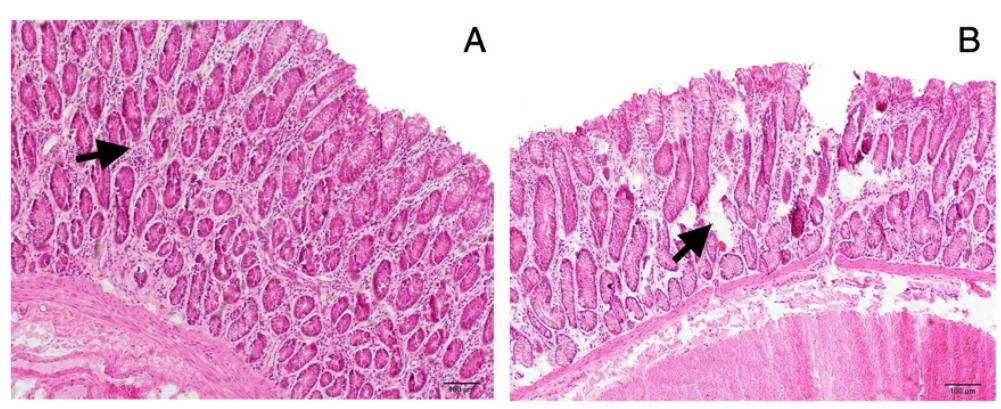

Figure 2 Comparisons of morphological of the colonic mucosa between HC and LC goats. Colonic mucosa epithelium $(n=6)$ from each group were processed for morphological evaluation: colon section of the (A, scale bar $=100 \mu \mathrm{m})$ LC group; (B, scale bar $=100 \mu \mathrm{m}) \mathrm{HC}$ group. Arrow indicates the damage of the colonic mucosa epithelium.

show significant difference between $\mathrm{HC}$ and LC goats $(p>0.05$, Figure 5).

\section{Protein expression in the colonic mucosa}

The level of claudin-1 $(p<0.05)$, claudin-4 $(p<0.05)$ and actived-caspase-3 $(p<0.05)$ proteins expression in the colonic mucosa was significantly up-regulated in $\mathrm{HC}$ goats compared to LC. However, occludin and NF-kB proteins expression in the colonic mucosa was not altered by high concentrate diet treatment $(p>0.05)$ Figure 6.

\section{Discussion}

Feeding high-grain diets to lactating ruminants causes a high risk to damage the histological integrity and functions of ruminal epithelium in dairy cows $[3,4]$. However, information regarding the influence of high-concentrate diet on the hindgut epithelial structure, and the molecular events especially the alterations in $\mathrm{TJ}$ proteins and epithelial cells apoptosis status is currently unavailable. The present study reports for the first time that feeding high proportion of concentrate diet to lactating goats for 10 wks increase VFA concentrations in both ruminal fluid and colonic digesta. The severe damages of the colonic mucosa barrier indicated by widen TJs space and nuclear breakdown and mitochondrial swelling, which was associated with the activating of epithelial cells apoptosis showing by the significant increase of TUNEL-positive apoptotic cells and caspases activities. These results may provide new insights into the understanding the relationship between abnormal fermentation in the hindgut lumen and the damages to the intestinal mucosa barrier.

After 10 wks feeding, HC-fed goats showed a higher level of total VFA content in ruminal fluid compared to LC goats. As previous report [10], our results showed that a significant increase of both total VFA and starch content in the colonic digesta observed in HC goats. It's
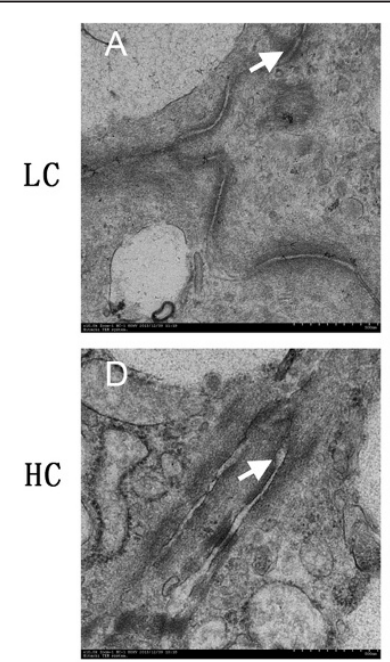

T J
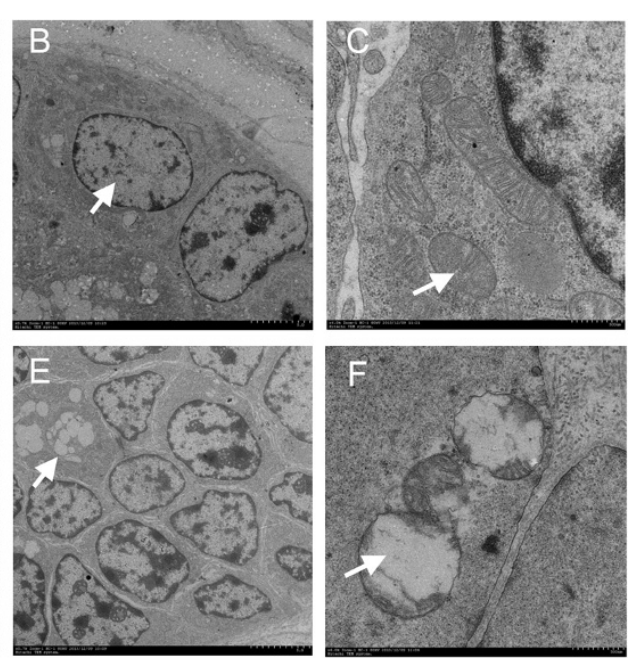

nucleus

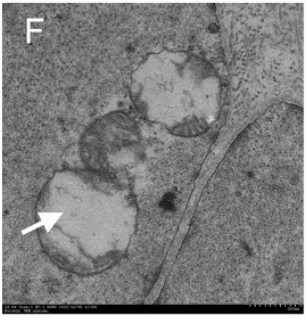

mitochondria

Figure 3 Comparisons of ultrastructure of the colonic mucosa between HC and LC goats. Colonic mucosa epithelium $(n=6)$ from each group were processed for ultrastructure evaluation: colon section of the (A) TJs of LC group; (B) nuclear of LC group; (C) mitochondria of LC group; (D) TJs of HC group; (E) nuclear of HC group; (F) mitochondria of HC group (transmission electron microscopy, $\times 10000)$. Arrow indicates the location of the TJs, nuclear or mitochondria (Scale bar $=500 \mathrm{~nm}$ ). 

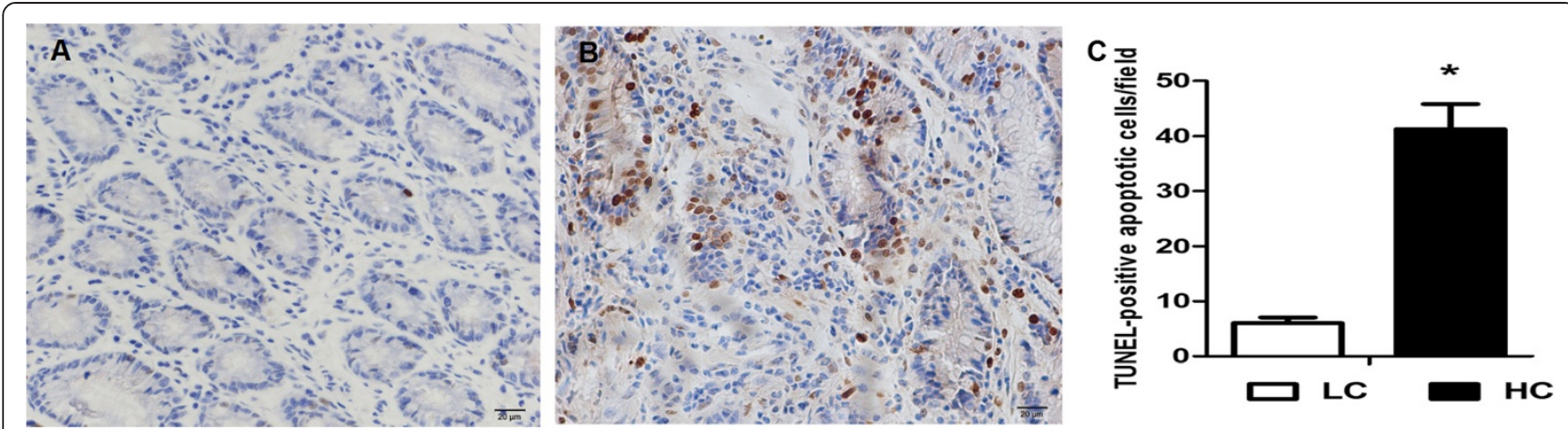

Figure 4 Comparisons of TUNEL of the colonic mucosa between HC and LC goats. Colonic mucosa epithelium ( $\mathrm{n}=6$ ) from each group were processed for TUNEL-positive apoptotic cells evaluation: colon section of the (A, scale bar = $20 \mu \mathrm{m}) \mathrm{LC}$ group; $(\mathbf{B}$, scale bar = $20 \mu \mathrm{m}) \mathrm{HC}$ group. C: Analysis of the positive apoptotic cells. The results were expressed as mean \pm SEM. The data were analyzed by Independent-Samples $T$ test using the Compare Means of SPASS 11.0 for Windows (StaSoft Inc, Tulsa, OK, USA). * $p<0.05$ vs. LC.

reported that a single mild episode of subacute ruminal acidosis (SARA) does not affect ruminal barrier function in the short term [29], and the author inferred that increased acid insult severity might induce sustained epithelial barrier dysfunction. In production practice, impairment of intestinal epithelial barrier function is frequently found in high-producing ruminants which are usually fed a highly concentrated diet for relatively long time. Paralleled the accumulation of VFA and starch in colonic digesta, a profound structural disruptions in the colonic mucosa was observed in $\mathrm{HC}$ goats with widen TJs, cell nuclear breakdown and mitochondrial swelling. In contrast, LC goats displayed the integrity of mucosa barrier with normal histological structure and cellular ultrastructure in the colonic epithelium. Our results

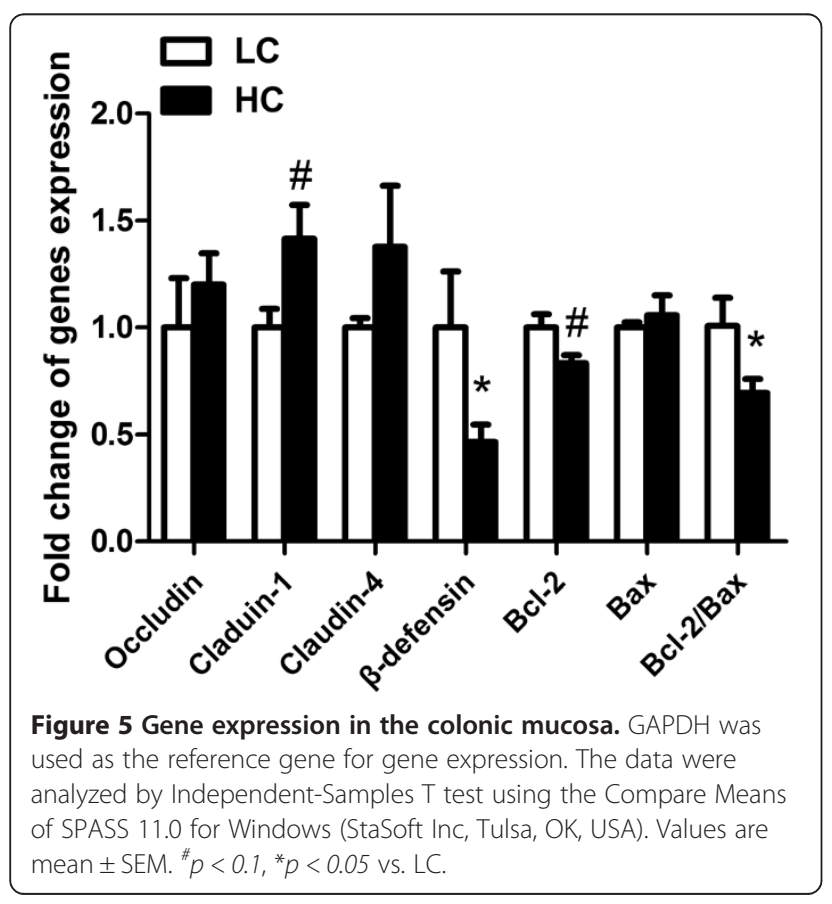

demonstrate that, as previous reports in ruminal epithelial barrier $[21,28]$, feeding high-concentrate diet to lactating goats for long period resulted in the disruption of epithelial structure in the colonic mucosa.

Luminal acidity is one of the most important factors to determine the status of epithelial barrier. It's reported that acetic acid $(0.1 \mathrm{M})$ showed a time- and $\mathrm{pH}$-dependent ability to damage colonic epithelium in pig [30]. In human colon adenocarcinoma cell line, acetate treatment in the $\mathrm{pH}$ range of 6.0 to 7.0 induced cell apoptosis rather than necrosis, while acetate treatment at $\mathrm{pH} 5.5$ caused cell necrosis [11]. In addition, higher acidity induces apoptosis and inhibits cell proliferation in colorectal carcinoma cell lines [12]. In this study, the level of acetate and other VFA components in the colonic digesta was markedly increased in HC goats. TUNEL results showed that in parallel to the obvious damages to the colonic mucosa, higher amount of positive apoptotic cells were detected in the colonic mucosa of $\mathrm{HC}$ goats than that of LC counterparts. Moreover, $\mathrm{HC}$ goats demonstrated a marked appearance of dark brown apoptotic cells and intercellular apoptotic fragments compared to LC goats. Previous studies suggested that the short-chain fatty acids increased localization epithelial apoptosis and necrosis and these changes are dependent on caspase activation [11]. In epithelial tissues, tight junction damage is usually thought of as a downstream consequence of caspase cleavage during the apoptotic process [15]. In the present study, the activities of caspase- 3 and caspase-3/7 were markedly enhanced in the colonic epithelium of $\mathrm{HC}$ goats compared to control. In addition, the level of activated-caspase- 3 protein was also enhanced in the colonic epithelium of $\mathrm{HC}$ goats. As the previous report [31], our results showed that the ratio of bcl-2/bax mRNA expression was significant decreased in $\mathrm{HC}$ goats compared to control, which indicates the downregulation of the cellular anti-apoptotic ability in the colonic mucosa. Based on these results, we conclude that an increase of cellular apoptosis and a decrease in anti- 

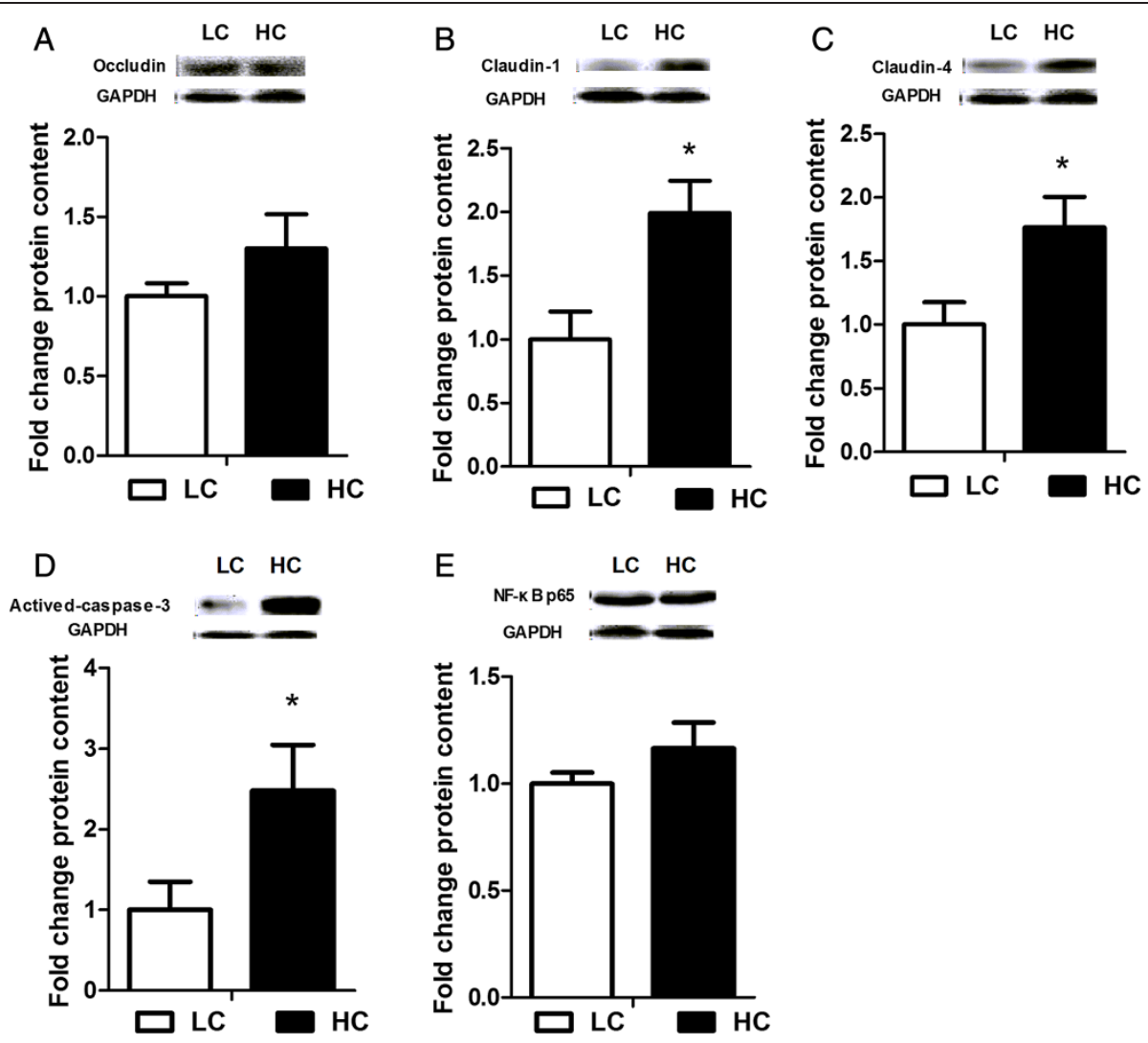

Figure 6 Protein expression in the colonic mucosa. Results of protein levels expressed as arbitrary units relative to GAPDH protein, fold change of Occludin (A), Claudin-1 (B), Claudin-4 (C), Actived-caspase-3 (D) and NF-kB p65 (E) protein content in the colonic mucosa. Values are mean \pm SEM. The data were analyzed by Independent-Samples T test using the Compare Means of SPASS 11.0 for Windows (StaSoft Inc, Tulsa, OK, USA). ${ }^{*} p<0.1,{ }^{*} p<0.05$ vs. LC.

apoptotic ability may contribute to the damages of the colonic mucosa caused by $\mathrm{HC}$ diet.

TJ proteins defects or enrichment are causatively associated with a variety of human diseases, demonstrating that TJ proteins play important roles in human physiology [16,32-34]. In this study, accompanied the disruption and expansion of intercellular TJs morphology, HC goats demonstrated a marked up-regulation of $\mathrm{TJ}$ protein expression including claudin- 1 and -4 in the colonic mucosa. There are several possible explanations for these changes in TJ proteins. As previous reports [35,36], the claudins comprise a multigene family, and the different claudins have diverse functions depending on cell type and the host organism. It's reported that the claudin-1 does not localize to the TJ, which indicates no contribution of claudin-1 to the barrier function [37]. Moreover, recent studies have revealed that claudins may be involved in regulating cell proliferation and signaling [38-41]. Claudin- 4 has been suggested as one of these unique types of claudins, which strongly participated in membrane permeation via paracellular pathway in both normal and disease condition [42,43]. Claudin-4 expression was significantly increased in the intestinal mucosa lesion [39]. Another kind of TJ protein, Occludin has a transmembrane region and may play both a functional and structural role defining the paracellular barrier [44]. High-grain diet caused a significant change of occludin mRNA and protein expression in ruminal epithelium [25]. However, our data showed that there was no significant difference in the expression of occludin mRNA and protein in the colonic mucosa between $\mathrm{HC}$ and LC goats. Nevertheless, the true causal relationship between TJs disruption and the increase of claudins protein in the colonic mucosa of $\mathrm{HC}$ goats needs to be further elucidated.

As one of the most potent inflammatory mediators and a major structural component of Gram-negative bacteria, LPS has been hypothesized to form an important risk factor of intestinal bowel disease (IBD) [45]. It's widely accepted that Toll-like receptors (TLRs) in the intestine epithelium play a key role in maintaining the homeostasis by recognizing ligands known as microbial-associated molecular patterns derived from both pathogenic and nonpathogenic bacteria $[18,19]$. MyD88-dependent pathway is the downstream signals of TLR-4, and initiation of MyD88-dependent pathway could lead to activation of NF- $\mathrm{kB}$ and transcription of several pro-inflammatory 
genes [18]. NF- $\kappa B$ activation has been detected in the mucosa of patients with IBD and in murine colitis model, and inhibition of NF-kB with a specific p65 antisense oligonucleotide is effective in preventing experimental models of IBD and efficiently down-regulates cytokine production [26]. In ruminants, the increase in rumen LPS concentration due to increased starch feeding is well documented $[10,46]$. The increase in LPS concentration in the cecum in grain-based SARA challenges are due to increased growth of LPS-producing bacteria in the hindgut but not in the rumen [43]. Van Kessel et al. observed an increase of the gram-negative bacteria in cecal digesta after postruminal infusion of starch [47]. In this study, a significant increase of LPS in ruminal fluid was observed in $\mathrm{HC}$ goats, and starch content in colonic digesta was also markedly increased compared to LC goats. In a good agreement with previous studies, a significant increase of LPS in cecal digesta was observed in the present study (data not shown). However, LPS concentration in colonic digesta was not altered after feeding $\mathrm{HC}$ diet for 10 wks. The differences in adaptation time to diet and different hindgut location between these studies may explain the discrepancy results of LPS production in hindgut digesta. In order to further investigate the influence of LPS signal pathway on the epithelial cellular function, NF- $\mathrm{K}$ B protein expression in the colonic mucosa was detected by western blot. No significant difference of NF-k B protein was observed in the colonic mucosa between $\mathrm{HC}$ and LC goats. Taken together, these results suggested that LPS cascade signal may not contribute to the damages of the colonic mucosa induced by feeding $\mathrm{HC}$ diet for a long-term in lactating goats.

\section{Conclusion}

In summary, we report herein for the first time that long-term feeding $\mathrm{HC}$ diet to lactating goats caused the accumulation of VFA in ruminal fluid and colonic digesta and damages to the colonic mucosa barrier induced by activating cells apoptosis. For HC goats, the increase of acidity rather than LPS in colonic digesta is mostly responsible for the disruption of the colonic epithelial barrier.

\section{Additional file}

Additional file 1: Animal research: reporting in vivo experiments.

\section{Competing interests}

The authors declare that they have no financial, personal or professional interests that would have influenced the content of the paper or interfered with their objective assessment of the manuscript.

\section{Authors' contributions}

TS: performed the experiment and drafted the manuscript. HD YD JT: performed the experiment and analyzed the data. RZ: contributed in experiment design and manuscript revision. YN: conceived the idea, designed the experiment, and finalized the manuscript. All authors read and approved the final manuscript.

\section{Acknowledgements}

This work was supported by National Basic Research Program of China (Project No. 2011CB100802) and National Nature Science Foundation of China (Project No. 31272470) and A Project Funded by the Priority Academic Program Development of Jiangsu Higher Education Institutions (PAPD).

Received: 11 April 2014 Accepted: 23 September 2014

Published online: 26 September 2014

\section{References}

1. Gaebel G, Bell M, Martens $\mathrm{H}$ : The effect of low mucosal pH on sodium and chloride movement across the isolated rumen mucosa of sheep. Q J Exp Physiol 1989, 74(1):35-44.

2. Plaizier JC, Krause DO, Gozho GN, McBride BW: Subacute ruminal acidosis in dairy cows: the physiological causes, incidence and consequences. Veterinary J 2008, 176(1):21-31.

3. Emmanuel DG, Madsen KL, Churchill TA, Dunn SM, Ametaj BN: Acidosis and lipopolysaccharide from Escherichia coli B:055 cause hyperpermeability of rumen and colon tissues. J Dairy Sci 2007, 90(12):5552-5557.

4. Steele MA, Croom J, Kahler M, AlZahal O, Hook SE, Plaizier K, McBride BW: Bovine rumen epithelium undergoes rapid structural adaptations during grain-induced subacute ruminal acidosis. Am J Physiol Regul Integr Comp Physiol 2011, 300(6):R1515-R1523.

5. Graham C, Simmons NL: Functional organization of the bovine rumen epithelium. Am J Physiol Regul Integr Comp Physiol 2005, 288(1):R173-R181.

6. Penner GB, Steele MA, Aschenbach JR, McBride BW: Ruminant Nutrition Symposium: Molecular adaptation of ruminal epithelia to highly fermentable diets. J Anim Sci 2011, 89(4):1108-1119.

7. Stumpff F, Georgi Ml, Mundhenk L, Rabbani I, Fromm M, Martens H, Gunzel D: Sheep rumen and omasum primary cultures and source epithelia: barrier function aligns with expression of tight junction proteins. J Exp Bio/ 2011, 214(Pt 17):2871-2882.

8. Dong G, Liu S, Wu Y, Lei C, Zhou J, Zhang S: Diet-induced bacterial immunogens in the gastrointestinal tract of dairy cows: impacts on immunity and metabolism. Acta Vet Scand 2011, 53:48.

9. Gressley TF, Hall MB, Armentano LE: Ruminant Nutrition Symposium: Productivity, digestion, and health responses to hindgut acidosis in ruminants. J Anim Sci 2011, 89(4):1120-1130.

10. Li S, Khafipour E, Krause DO, Kroeker A, Rodriguez-Lecompte JC, Gozho GN, Plaizier JC: Effects of subacute ruminal acidosis challenges on fermentation and endotoxins in the rumen and hindgut of dairy cows. J Dairy Sci 2012, 95(1):294-303.

11. Lan A, Lagadic-Gossmann D, Lemaire C, Brenner C, Jan G: Acidic extracellular $\mathrm{pH}$ shifts colorectal cancer cell death from apoptosis to necrosis upon exposure to propionate and acetate, major end-products of the human probiotic propionibacteria. Apoptosis 2007, 12(3):573-591.

12. Marques C, Oliveira CS, Alves S, Chaves SR, Coutinho OP, Corte-Real M, Preto A: Acetate-induced apoptosis in colorectal carcinoma cells involves lysosomal membrane permeabilization and cathepsin $D$ release. Cell Death \& Disease 2013, 4:e507.

13. Strater J, Wellisch I, Riedl S, Walczak H, Koretz K, Tandara A, Krammer PH, Moller P: CD95 (APO-1/Fas)-mediated apoptosis in colon epithelial cells: a possible role in ulcerative colitis. Gastroenterology 1997, 113(1):160-167.

14. Nagata S: Apoptosis by death factor. Cell 1997, 88(3):355-365.

15. Beeman N, Webb PG, Baumgartner HK: Occludin is required for apoptosis when claudin-claudin interactions are disrupted. Cell Death \& Disease 2012, 3:e273.

16. Turner JR: Intestinal mucosal barrier function in health and disease. Nat Rev Immunol 2009, 9(11):799-809.

17. Wardill HR, Bowen JM: Chemotherapy-induced mucosal barrier dysfunction: an updated review on the role of intestinal tight junctions. Curr Opinion Support Palliat Care 2013, 7(2):155-161.

18. Akira S: Pathogen recognition by innate immunity and its signaling. Proc Jpn Acad Ser B Phys Biol Sci 2009, 85(4):143-156.

19. Neish AS: Microbes in gastrointestinal health and disease. Gastroenterology 2009, 136(1):65-80.

20. Sharma R, Young C, Neu J: Molecular modulation of intestinal epithelial barrier: contribution of microbiota. J Biomed Biotechnol 2010, 2010:305879. 
21. Poltorak A, He X, Smirnova I, Liu MY, Van Huffel C, Du X, Birdwell D, Alejos E, Silva M, Galanos C, Freudenberg M, Ricciardi-Castagnoli P, Layton B, Beutler B: Defective LPS signaling in $\mathrm{C} 3 \mathrm{H} / \mathrm{HeJ}$ and $\mathrm{C} 57 \mathrm{BL} / 10 \mathrm{ScCr}$ mice: mutations in Trr4 gene. Science 1998, 282(5396):2085-2088.

22. Takeda K, Kaisho T, Akira S: Toll-like receptors. Annu Rev Immunol 2003, 21:335-376.

23. Baldwin AS Jr: The NF-kappa B and I kappa B proteins: new discoveries and insights. Annu Rev Immunol 1996, 14:649-683.

24. Khafipour E, Krause DO, Plaizier JC: A grain-based subacute ruminal acidosis challenge causes translocation of lipopolysaccharide and triggers inflammation. J Dairy Sci 2009, 92(3):1060-1070.

25. Liu JH, Xu TT, Liu YJ, Zhu WY, Mao SY: A high-grain diet causes massive disruption of ruminal epithelial tight junctions in goats. Am J Physiol Regul Integr Comp Physiol 2013, 305(3):R232-R241.

26. Neurath MF, Pettersson S, Meyer zum Büschenfelde KH, Strober W: Local administration of antisense phosphorothioate oligonucleotides to the p65 subunit of NF-kappa B abrogates established experimental colitis in mice. Nat Med 1996, 2(9):998-1004.

27. Gozho GN, Plaizier JC, Krause DO, Kennedy AD, Wittenberg KM: Subacute ruminal acidosis induces ruminal lipopolysaccharide endotoxin release and triggers an inflammatory response. J Dairy Sci 2005, 88(4):1399-1403.

28. Yue C, Ma BQ, Zhao YZ, Li QR, Li JS: Lipopolysaccharide-Induced Bacterial Translocation Is Intestine Site-Specific and Associates with Intestinal Mucosal Inflammation. Inflammation 2012, 35(6):1880-1888.

29. Penner GB, Oba M, Gabel G, Aschenbach JR: A single mild episode of subacute ruminal acidosis does not affect ruminal barrier function in the short term. J Dairy Sci 2010, 93(10):4838-4845.

30. Argenzio RA: Comparative pathophysiology of nonglandular ulcer disease: a review of experimental studies. Equine Veterinary J Supp/ 1999, 29:19-23.

31. Yang SJ, Lee SA, Park MG, Kim JS, Yu SK, Kim CS, Kim JS, Kim SG, Oh JS, Kim HJ, Chun HS, Kim YH, Kim do K: Induction of apoptosis by diphenyldifluoroketone in osteogenic sarcoma cells is associated with activation of caspases. Oncol Rep 2014, 31(5):2286-2292.

32. Heiskala M, Peterson PA, Yang Y: The roles of claudin superfamily proteins in paracellular transport. Traffic 2001, 2(2):93-98.

33. John LJ, Fromm M, Schulzke JD: Epithelial barriers in intestinal inflammation. Antioxid Redox Signal 2011, 15(5):1255-1270.

34. Schulzke JD, Fromm M: Tight junctions: molecular structure meets function. Ann N Y Acad Sci 2009, 1165:1-6.

35. Van Itallie CM, Anderson JM: Claudins and epithelial paracellular transport. Annu Rev Physiol 2006, 68:403-429.

36. Furuse $M$, Hirase $T$, Itoh M, Nagafuchi A, Yonemura S, Tsukita S, Tsukita S: Occludin - a Novel Integral Membrane-Protein Localizing at Tight Junctions. J Cell Bio/ 1993, 123(6):1777-1788.

37. Poritz LS, Harris LR 3rd, Kelly AA, Koltun WA: Increase in the tight junction protein claudin-1 in intestinal inflammation. Dig Dis Sci 2011, 56(10):2802-2809.

38. Swisshelm K, Macek R, Kubbies M: Role of claudins in tumorigenesis. Adv Drug Deliver Rev 2005, 57(6):919-928.

39. Tamura A, Kitano Y, Hata M, Katsuno T, Moriwaki K, Sasaki H, Hayashi H, Suzuki Y, Noda T, Furuse M, Tsukita S, Tsukita S: Megaintestine in claudin-15-deficient mice. Gastroenterology 2008, 134(2):523-534

40. Tsukita S, Yamazaki Y, Katsuno T, Tamura A, Tsukita S: Tight junction-based epithelial microenvironment and cell proliferation. Oncogene 2008, 27(55):6930-6938.

41. Kawai $Y$, Hamazaki $Y$, Fujita H, Fujita A, Sato T, Furuse M, Fujimoto T, Jetten AM, Agata $Y$, Minato N: Claudin-4 induction by E-protein activity in later stages of $\mathrm{CD} 4 / 8$ double-positive thymocytes to increase positive selection efficiency. Proc Natl Acad Sci U S A 2011, 108(10):4075-4080.

42. Oshima T, Sasaki M, Kataoka H, Miwa H, Takeuchi T, Joh T: Wip1 protects hydrogen peroxide-induced colonic epithelial barrier dysfunction. Cell Mol Life Sci 2007, 64(23):3139-3147.

43. Takizawa $Y$, Kishimoto $H$, Kitazato $T$, Tomita M, Hayashi M: Changes in protein and mRNA expression levels of claudin family after mucosal lesion by intestinal ischemia/reperfusion. Int J Pharm 2012, 426(1-2):82-89.

44. Matter K, Balda MS: Occludin and the functions of tight junctions. Int Rev Cytol 1999, 186:117-146.

45. Caradonna L, Amati L, Magrone T, Pellegrino NM, Jirillo E, Caccavo D: Enteric bacteria, lipopolysaccharides and related cytokines in inflammatory bowel disease: biological and clinical significance. $J$ Endotoxin Res 2000, 6(3):205-214.

46. Zebeli Q, Ametaj BN: Relationships between rumen lipopolysaccharide and mediators of inflammatory response with milk fat production and efficiency in dairy cows. J Dairy Sci 2009, 92(8):3800-3809.

47. Van Kessel JS, Nedoluha PC, Williams-Campbell A, Baldwin RL, McLeod KR: Effects of ruminal and postruminal infusion of starch hydrolysate or glucose on the microbial ecology of the gastrointestinal tract in growing steers. J Anim Sci 2002, 80(11):3027-3034.

doi:10.1186/s12917-014-0235-2

Cite this article as: Tao et al:: A high-concentrate diet induced colonic epithelial barrier disruption is associated with the activating of cell apoptosis in lactating goats. BMC Veterinary Research 2014 10:235.

\section{Submit your next manuscript to BioMed Central and take full advantage of:}

- Convenient online submission

- Thorough peer review

- No space constraints or color figure charges

- Immediate publication on acceptance

- Inclusion in PubMed, CAS, Scopus and Google Scholar

- Research which is freely available for redistribution 